\title{
TERRACOTAS DE IBIZA EN EL MUSEO DE MAHON (MENORCA)
}

\author{
M. Pilar SAN NICOLAS PEDRAZ
}

En el Museo Provincial de Bellas Artes de Mahón, instalado en la Casa de la Cultura o Palacio de Archivos. Bibliotecas y Museos (1) se encuentra, entre otros objetos que han ido ingresando desde su fundación en 1948, una pequeña colección de terracotas procedentes de la lbiza cartaginesa en calidad de depósito, que perteneció a D.A. Vives y Escudero.

Todas estas piezas, nueve en total, aún son inéditas puesto que no han sido recogidas en el reciente Corpus que la Dra. M.J. Almagro ha realizado sobre las terracotas de Ibiza (2).

Es imposible saber con exactitud las procedencias exactas de esta colección. así como su contexto arqueológico. Sin duda fueron halladas en excavaciones de principio de siglo, y posiblemente pertenezcan a la gran necrópolis de Puig des Molins, como la inmensa mayoría de los tipos similares.

1. Figura femenina. de cuerpo entero, entronizada (Lám. I). Número de inventario de Museo 290. Altura, $17.2 \mathrm{~cm}$. Barro de color ocre claro. Realizada con molde bivalvo, hueca. de base abierta y la parte posterior lisa. Completa. Conserva restos de pintura de color rojo en la falda.

La figura está representada sentada sobre un trono de respaldo medio, con braz.os y patas sólidas (3). Sobre la cabeza lleva un alto polos cilíndrico, denominado "Kidaris". de donde le cae un velo o himation hasta las rodillas cubriéndole la espalda (4). Por debajo de la diadema asoma el cabello tratado en una fila. La cara es ancha y redondeada. de facciones carnosas y regulares, la boca presenta la típica sonrisa de tradición griega arcaica. Viste chiton con larga manga. Con la mano izquierda sujeta un niño que lleva sentado en las rodillas, el otro brazo cae verticalmente por la rodilla derecha. Los pies están apoyados sobre un ęscabel.

(1) SERRA. M.L..: I.a Casa de la Cultura de Mahon. "Boletín de la Dirección General de Archivos y Bibliotecas", 33, Madrid 1955, págs. 25-28.

(2) ALMAGRO GORBEA, M.J.. Corpus de las terracotas de Ibiza. "Bibliotheca Praehistorica Hispana", vol. XVIII. Madrid 1980.

(3) Esta clase de trono corresponde al tipo 4 de GISELA M.A. RICHTER: Ancient Furniturc. A Histon of Greek, Etruscan and Roman Fumiture. Oxford 1926, págs. 28 y 29.

(4) Un ejemplo de esta tiara y velo, característico de divinidades, se encuentra en los bajorrelieves ninivitas del palacio de Sennacherif en Kouyunjik. Según los últimos estudios se trata de la huida de Luli, rey de Tiro y de Sidón en el año 701 a. JC. (huyendo de Tiro). E. BARNETT: : Shippirg in the Near East. "Antiquity" XXXII, 1958, pág. 226. 


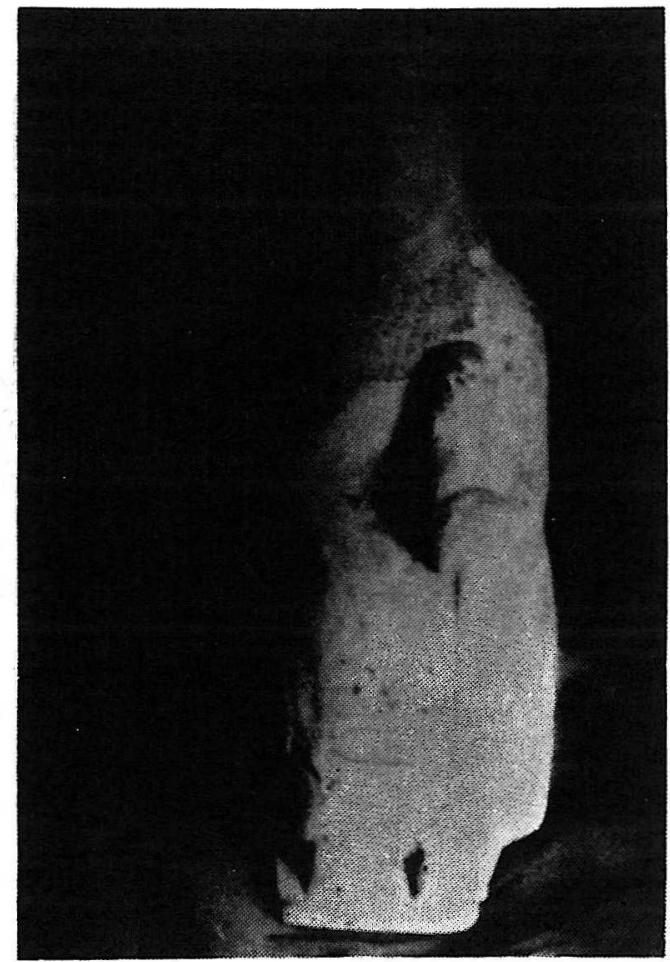

Lámina I

Este tipo de figuras las encontramos en Rodas, $y$ han sido fechadas por el grupo de tumbas y por su estilo griego arcaico a finales del siglo VI-V a. JC. (5). Chr. Blinkerberg (6) las encuadra en los tipos simples. Se encuentra bastante difundido por todo el archipiélago jónico y por la isla de Sicilia (7).

(5) HIGGINS, R.A.: Catalogue of the terracottas in the department of greek. and roman antiquities, British Museum. Oxford 1969, pág. 51.

(6) BLINKENBERG, CHR.: Lindos. Fouilles de l'acropole 1902-1914. I. Les petits objets. Berlin 1931, pág. 515.

(7) WINTER, F.: Die Tipen der figürlichen Terrakoten. I. Berlin-Stuggart 1903. lám. 43,5; lám. 120, 2. BLINKENBERG, CHR.: op. cit. pảgs. 514-515, lám 96, núms. 21 19-2124. BREITENSTEIN, N.: Catalogue of terracuttas in the Danish National Museum. Copenhague 1941, pág. 13, lám. 12, núms. 121 y 122; págs. 24-25, lám. 22, núms. 236-237. MOLLARD-BESQUES, S.: Catalogue raisonme des figurines et reliefs en terre cuite grecs, etrusques et romans. I. Epoque préhellénique géométrique, archaïque et classique. París 1954, pág. 36, lảm. XXVI, núm. B. 260-270; pág. 76, lám. XLIV, núm. B. 532. ADAMESTEANU, D.: Gela. Nuovi scavi. "Notizie degli scavi di antichità", 1960 , págs. 229-230, figs: 18, núm. 1; 19, núms. 1-2. ORLANDINI, P.: L.o scavo del Thesmophorion di Bitalemi e il culto delle Divinitá ctonie a Gela. "Kokalos" XII, 1966, pág. 24, lám. XIX, figs. 2-3. HIGGINS, R.A.: op. cit. pág. 51, lám. 13, núms. 68 y 70; pág. 52, lám. 14 núms. 69, 71-73. 
En Cartago, en el Museo Nacional existen dos ejemplares localizados en la Necrópolis de Doüimes en 1895 por el P. Delattre (8). Otro se guarda en el Museo del Bardo, procedente de la Necrópolis de Dermech, excavada por P. Gauckler en 1902 (9).

En lbiza se descubrió en la Necrópolis de Puig des Molins, en la campaña de 1966. en el Sector II, tumba número III realizada, por M.J. Almagro una pieza similar que actualmente se conserva en el museo Monográfico de Puig des Molins (10). Junto a ella se localizó otra figura femenina entronizada de un tipo idéntico al que posteriormente estudiaremos (11), una campanita de bronce, un fragmento de la parte inferior de un vaso cerámico indeterminado $y$ varios fragmentos indefinidos de un pequeño recipiente de bronce.

Dentro de este tipo de figuras existen varias y pequeñas modificaciones: de mayor altura y con más detalle. con un trono sin brazos y con alto respaldo. el himattion cubriéndole el pecho: con el trono más ancho y sin respaldo: llevando una paloma: carente de atributo.

La figura con un niño en brazos también se ha encontrado en el yacimiento de la Acrópolis de Lindos (12), pero difiere de nuestro ejemplar en la forma de llevar el infante. Esta también lo tiene sentado sobre las rodillas. pero se encuentra mirando de lado, mientras que el de Ibiza está de frente.

Alude a la diosa madre con el niño divino, que representa la sublime misión de la maternidad. y por lo tanto la idea de la fecundidad, cuyo culto viene a ser el mismo de la antigua "Ciran Diosa Madre" del Mediterráneo, ya que todas las divinidades femeninas son las mișmas en todas las culturas del mundo antiguo, variando únicamente el nombre. El trono, símbolo de realeza y majestuosidad, el escabel y su alto polos cilíndrico nos señalarían a su vez el carácter divino y supremo de esta figura, que probablmeente aquí se refiera a la gran divinidad del panteón cartaginés anteriormente al siglo $\mathrm{V}$. $a$. JC.. Astarté, que fue suplantada a partir de este siglo por Tanit (13).

Por tanto, esta figura ibicenca parece, al igual que el ejemplar de Puig des Molins y los de Cartago, que fue importada directamente de Rodas: cronológicamente se puede situar a finales del siglo VI o principios del V.a. JC.

(8) BERGER. Ph. Mluséc Lavigerie de Saint-Louis de Carthage. I. Antiquités puniques. Paris 1900, págs. 98 y 99 , lám XV, núms. 1-2.

(9) GAUKLER, P. y varios: Catalogue du Musée Alaoui (Supplèment). París 1910, pág. 151, lám. LXXV, 5 .

(10) ALMAGRO GORBEA, M.J.: Excal'aciones arqueuligicas en Ibiza: "Excavaciones Arqueológicas en España”. núm. 56, 1967, pảg. 28, lám. XIII, núm. 2.

(11) Véase la figura 2.

(12) BLINKENBERG, CHR.: op. cit. pág. 515, läm. 96, núm. 2125.

(13) PICARD, G. CH.: Les religions de l'A frique antique. París 1954, pág. 56 y ss. 
2. Figura femenina, de cuerpo entero, sentada en un trono idéntico al de la figura anterior (Lám. II). Número de inventario de Museo 238. Altura, $9,5 \mathrm{~cm}$. Barro de color ocre claro. Realizada con molde bivalvo, hueca. de base abierta y la parte posterior lisa. Completa. Presenta bastantes concreciones calcáreas en la superficie.

La cabeza está tocada con un velo o himation que le cae hasta las rodillas cubriéndole la espalda. La cara se encuentra muy erosionada. Viste chiton con larga manga. Las manos se apoyan sobre las rodillas y los pies en un escabel.

Este tipo de figuras también lo encontramos en Rodas, y ha sido fecliado, al igual que el anterior por el grupo de tumbas y por su estilo griego arcaico a finales del siglo VI o principios del V a. JC. (14). Corresponde a los tipos simples (15) y también se extiende ampliamente por todo el archipiélago jónico (16).

En Cartago, en el Museo Nacional existen dos figuras similares halladas en las excavaciones de la necrópolis de Doüimes, en los años 1892-1894 por el P. Delattre (17).

Algunas veces este tipo de figuras aparece con la boca del vaso en la cabeza (18); una paloma entre los brazos (19), o con un león, en este último caso se ha identificado con la diosa Cibeles (20).

Esta figura de mujer entronizada con las manos sobre las rodillas sería la imagen de una diosa, puesto que es lógico pensar que una simple oferente o sacerdotisa no se representaría sentada en un trono, y posiblemente por

(14) HIGGINS, R.A.: op. cit. págs. 49 y 50.

(15) BLINKENBERG, CHR,: op. cit. págs. 515-517, láms. 96 y 97, núms. 2126-2138.

(16) WINTER, F.: op. cit. lám. 43,2; lám. 52,8; lám. 120,7. BLINKENBERG, CHR.: op. cit. págs. 5.15-517. láms. 96 y 97, núms. 2126-2138. BREITENSTEIN. N.. op. cit. pág. 18, lám. 18, núm. 159; pág. 20, lám. 20, núm. 180; pág. 25, lám, 24 núm. 235. MOLLARD-BESQUES, S.: op. cit. págs. 43-44, lám. XXXII, núms. B. 271-284: pág. 76, lám. XLIX, núms. B. 533 y 534. ADAMESTEANU, D. op. cit. págs. 229.230, figs. 19-20, núms. 2 y 5. ORLANDINI, P.: op. cit. pág. 24, lám. XIX, fig. 4. HIGGINS, R.A.. op. cit. pág. 50, lám. 15, núm. 65; pág. 65, lám. 22, núm. 126.

(17) DELATTRE, Revd. P.:: Quelques tombeaux de la Nécropole punique de Doüime (1892-1894). "Tirada aparte del Extrait des Missions catholiques". Lyon 1897, pág. 26. BERGER, PH.: op. cit. pág. 99, lảm. XV, núms. 3-6.

(18) WINTER, F.: op. cit. lám. 120, núm. 1. HIGGINS, R.A.: op. cit. págs. 49 y 50 , lám 14, núm. 63. FAEDO, L.: Contributo allo studio della coroplastica selimuntina, “Archeologia Classica", núm. 22, 1970, pág. 37, lám. IV, 1.

(19) ADAMESTEANU, D.: op. cit. págs. 229.230, fig. 19, núm. 1; fig. 20 , núm. 5.

(20) ORLANDINI, P.: op. cit. pág. 24, lám. XIX, fig. 1. FAEDO, L.: op. cit. pág. 37, lám. IV, 2. 


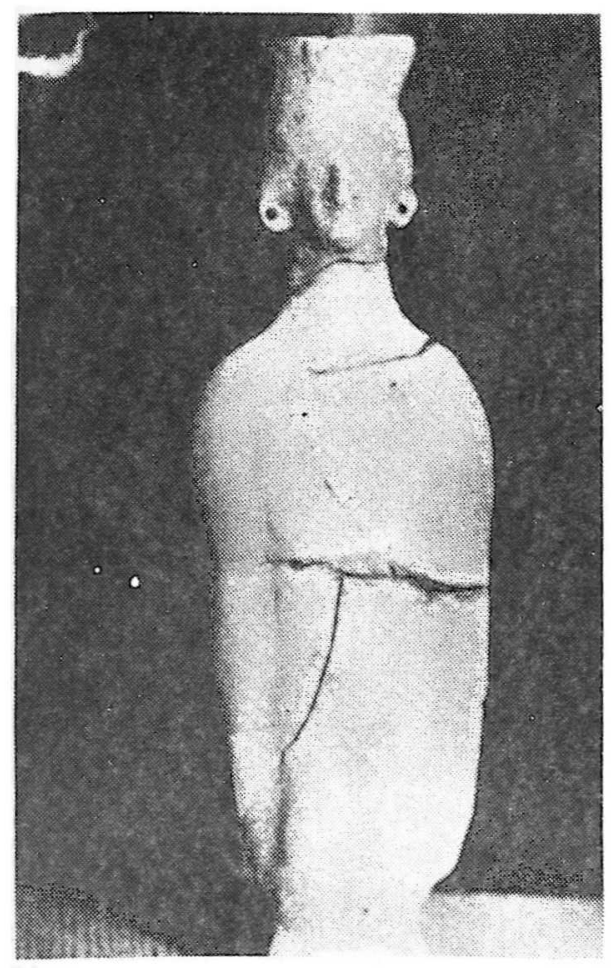

Lámina II.

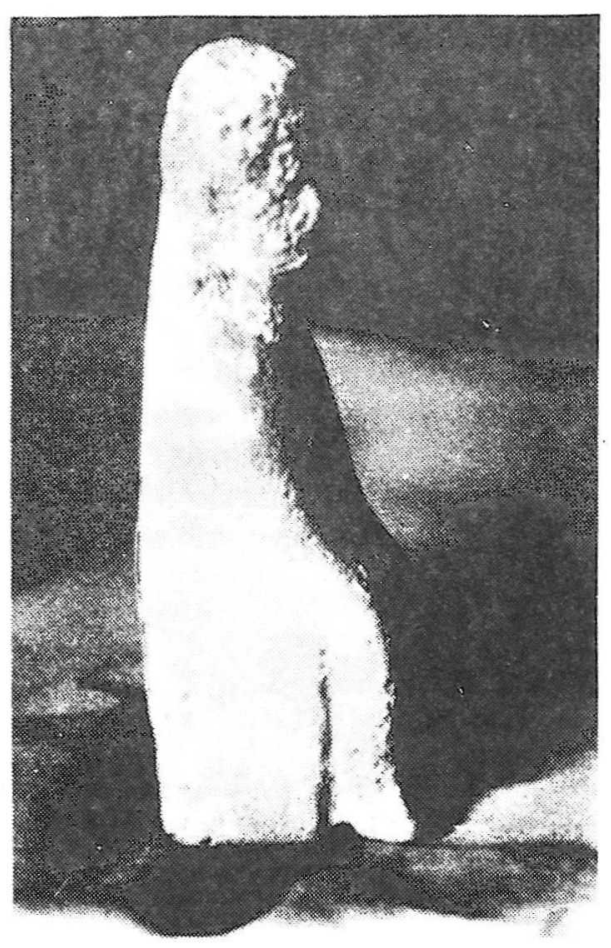

Lámina III. 
fecharse como la figura anterior a finales del siglo VI o principios del $\mathrm{V}$ a. JC., represente a la diosa fenicia Astarté con gesto sublime y apacible.

3. Figura femenina de cuerpo entero, de pie (Lám. III). Número de inventario de Museo, 39. Altura, $2,80 \mathrm{~cm}$. Barro de color ocre claro. Realizada con un solo molde, la parte posterior es hueca. Reconstruida de varios fragmentos, faltando uno en la parte derecha-inferior de la túnica.

Está representada encima de un delgado plinto o taburete de plegaria de forma rectangular. Tocada con un bajo y liso $\mathrm{K}$ alathos o polos, del cual se asoma el cabello que se halla muy erosionado. La cara es de facciones toscas. Los lóbulos de las orejas están perforados para la aplicación de pendientes metálicos, en la nariz también existe un orificio para el "nezem", moda semita que caracteriza al arte ebusitano. Viste larga túnica sin ningún detalle, percibiéndose el seno y el arranque de los brazos que posiblemente estarían aplicados y extendidos al frente como la mayoría de las figuras de este tipo. Pies descalzos.

La actitud de los brazos, extendidos al frente, es muy conocida en el Mediterráneo, e indica que son estatuas votivas de culto representando dioses o no. J.M. Blázquez nos señala varios paralelos de estos brazos (21) en varios bronces de Ugarit, en la diosa sentada de Beirut, en el dios Tell Zimizijan y en las sacerdotisas de Karkemis... También se encuentran en el mundo etrusco en la Artemis de Polledrara y en una estatua de bronce de Brolio, así como en los bronces ibéricos (22).

La forma aplicada de los brazos es una tradición de la coroplastia púnica. esta técnica casi no fue usada en Grecia, pero sí en Africa neopúnica del siglo I a. JC. (23).

Este tipo de figuras proceden de un modelo siciliota oriental de la segunda mitad del siglo $\mathrm{V}$ o comienzos del IV a. JC., concretamente de los talleres de Centuripe y Agrigento (24).

En Ibiza este modelo se difundió considerablemente, existen sesenta ejemplares de cuerpo entero y cincuenta y siete de medio cuerpo y bustos,

(21) BLAZQUEZ, J.M.: Coroplastia prerromana del Puig des Molins. "Archivo Español de Arqueología", 1964, pág. 47, notas 53-59.

(22) NICOLINI, G.: Les bronzez figurés des santuaires ibériques. Paris 1969, láms. XIV, 5 y 6 ; XV, 1-5; XVI, 1-6; XVII, 1-4; XX, 14; XXI, 14, XXIV, 4; XXVIII, 1 y 2.

(23) PICARD, C.: Figures de terre cuite du Musée de Prehistoire de Valencia. "Archivo de Prehistoria Levantina", XIII, 1972, pág. 75.

(24) LIBERTINI, G.: Centuripe. Catania 1926, láms. XIX y XX. MARCONI, P.. Agrigento Arcaica. Il santuario delle divinità chtonie e il tempio detto di Vulcano. Roma 1933, lám XIV. BLAZQUEZ, J.M.: op. cit. pág. 44. HIGGINS, R.A.: op. cit. pág. 322, lám. 193, núms. 1190-1191. BISI, A.M.: Le terrecotte figurate di tipo greco-punico di Ibiza.II. Museo Arqueologico di Barcellona. "Rivista di Studi Fenici", II, 2. 1974, págs. 236-238. 
percibiéndose algunas variantes por parte del coroplasta ebusitano, e incluso sacadas de diferente molde (25).

El plinto y el bajo o alto $r$ alathos de estas figuras ibicencas nos señalarian su carácter divino y no de unas simples oferentes, posiblemente Tanit, diosa suprema del panteón cartaginés, además debemos señalar que los brazos extendidos con palmas bien diferenciadas recuerdan al símbolo esquemático de esta diosa reiteradamente representado en numerosos objetos, fundamentalmente en las estelas (26), que es una figura femenina antropomorfizada. con representación triangular del cuerpo, brazos extendidos y palmas elevadas.

... Esta figura sería de producción local imitando el modelo siciliota, y por lo tanto de cronología más tardía. siglo III a. JC.

4. Figura femenina, de cuerpo entero, de pie (Lám. IV). Número de inventario de Museo 289. Altura conservada, $1,18 \mathrm{~cm}$. Barro de color ocre claro. Realizada con un solo molde, la parte posterior es hueca. Incompleta, le falta parte del velo y el final de la vestimenta. Está tocada con un bajo ¿alathos liso $y$ ahuecado velo en forma de concha que es típico en las terracotas griegas, a partir de la segunda mitad del siglo IV a. JC. (27). Por debajo de la diadema asoma el cabello inflado y sin trabajar. Facciones del rostro bastante borrosas. Viste peplos dórico y lleva en la mano derecha una antorcha encendida y en la izquierda un animal como of renda, que suele ser un cerdito, una paloma, un cervatillo, un pato o un cordero. En este caso resulta imposible adivinar lo que porta debido a la mala calidad de la pieza, pero. se la reconoce que se trata de este tipo de figuras por la antorcha.

Esta clase de figuras aparece en Grecia continental hacia la mitad del siglo V a. JC. representando a la diosa Deméter o Perséphone (Kore) (28).Más tarde se encuentra en la Magna Grecia, Tarento, Reggio de Calabria... (29), y en Sicilia, en los talleres de Siracusa, Magara Hyblaea, Gela, Agrigento, Selinunte... (30), extendiéndose con la penetración de la cultura helenística

(25) ALMAGRO GORBEA, M.J.. Corpus de las terracotas de Ibiza. ., op. cit. págs. 109-127. láms. XLVIII-LIX, 1, págs. 212-228, láms. CLII-CLVIII, 7.

(26) HOURS-MIEDAN, M.. Les représentations figurées stur les stèles de Carthage. "Cahiers de Byrsa" 1, 1951, págs. 26-31 láms. VI-1X. BISI, A.M.: Le stele puniche "Studi Semitici" 27, 1967, págs. 30, fig. 7.

(27) BISI, A.M.: Le terrecotte figurate. op. cit. pág. 240, nota 168.

(28) MOLLARD-BESQUES, S.. op. cit., pág. 59, lám X, 3.

(29) WINTER, F.. op. cit. lám. 117 , núms. 1-3, 5,9 y 10. LO PONTO, F.G.: Satyrion (Taranto). Scavi e ricerche nel luogo del piu antico ensediamento laconico in Puglia. "Notizie degli scavi di antichità", 1964, fig. 67.

(30) WINTER, F. op. cit. lám. 116, núm. 1-3,117, núms. 3,8, ORLANDINI, P. yADAMESTEANU, D.. Gela. Nuovi scavi. Notizie degli scavi di antichità, 1960 pág. 229, fig. 18,2. HIGGINS, R.A.. Greek terracottas. Londres 1967, pág. 87, lám. 37,B. 


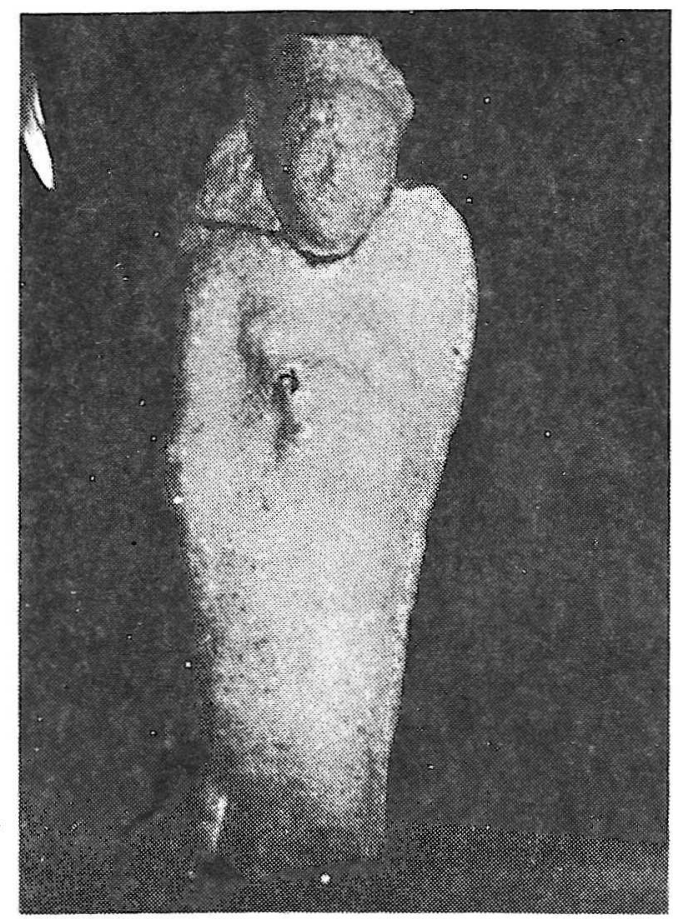

Lámina IV.

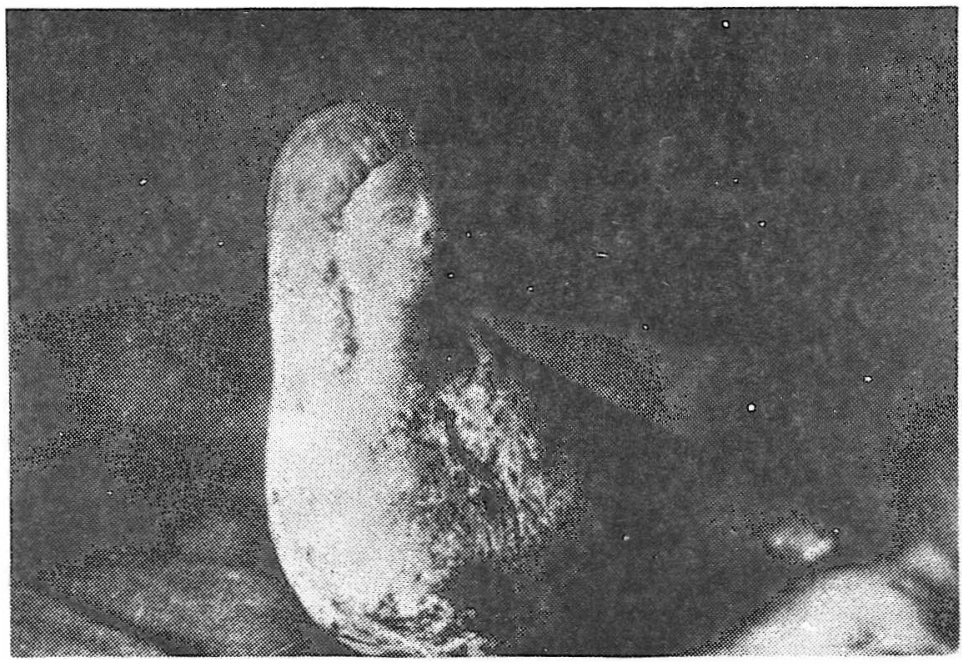

Lámina $V$. 


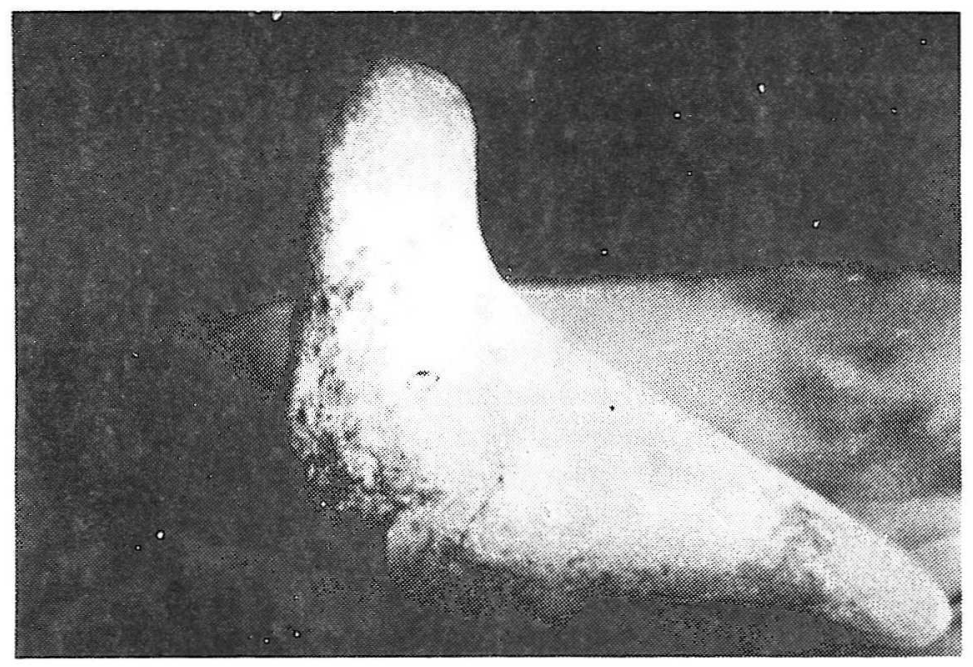

\section{Lámina VI.}

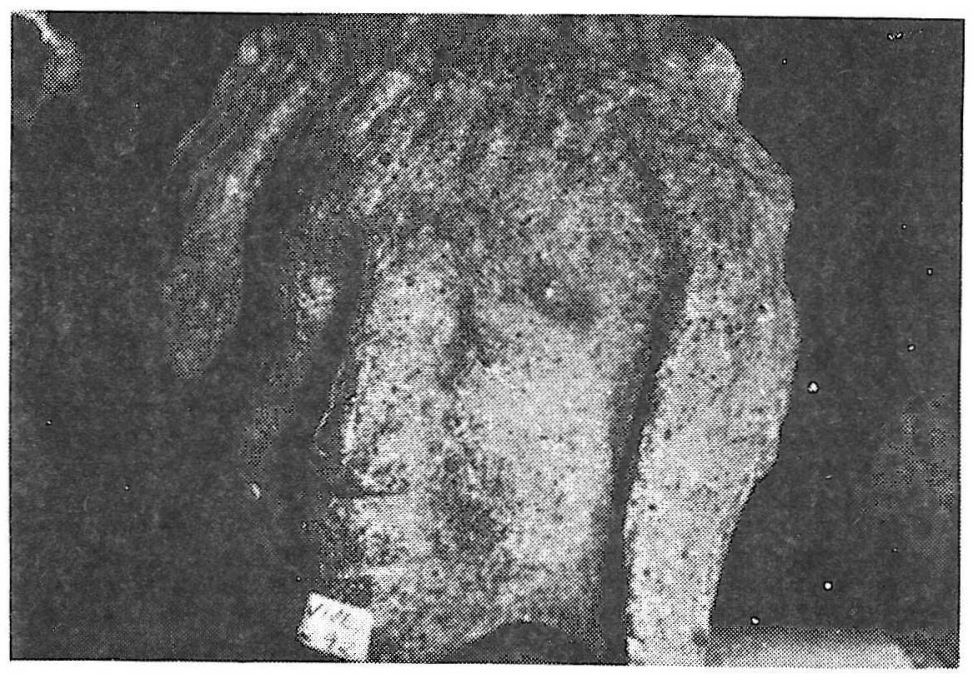

Lámina VII. 
por todo el Mediterráneo a partir de los siglos IV y III a.JC., Cerdeña (31), Cirenaica (32), Cartago (33), Península lbérica (34) e Ibiza (35), donde el número de ejemplares es bastante considerable como lo demuestran los hallazgos del santuario-cueva d'es Cuiram, necrópolis de Puig des Molins, santuario de Ca N'Ursul y el depósito de figuras de Puig, que hemos considerado como una Favissa (36).

La localización de estas figuras, como sus paralelos, nos llevan a pensar que se tratan de representaciones claras de las diosas griegas Deméter-Perséphone(Koré), cuyos cultos, al igual que Cartago (37) entrarian, sin sincretismos y en su forma pura, verificándose también en Ibiza el relato de Diodoro (XIV) acerca de que los cartagineses introdujeron el culto de estas diosas en el mundo púnico para expiar la destrucción y violación de sus templos cuando se apoderaron del Arrabal de Akradina, en Siracusa, en el año 396 a. JC

Esta figura deriva de una matriz siciliota del siglo IV a. JC., por lo tanto se puede situar cronológicamente a partir de mediados del siglo IV o III a. JC.

5. Figura de cuerpo entero con busto de mujer y cuerpo de ave (Láms. V-VI). Número de inventario de Museo 291 . Altura, $8,9 \mathrm{~cm}$. Barro de color ocre rojizo. Realizada con molde bivalvo. Completa. Conserva restos de poltcromía de color rojo (cuerpo) y blanco (pelo y cuerpo).

Se la aprecia un mechón ondulado del cabello que le cae a ambos lados del cuello.

Esta clase de figuras deriva de la sirena con la boca del vaso en la cabeza. tipo rodio de mediados del siglo VI a. JC. La encontramos difundida por

(31) MINGAZZINI, P.: Cagliari. Resti di Santuario pünico e altri nuderi a Mlonte di Piazza del Carmine. "Notizie degli scavi di antichità", 1948, pág. 239.

(32) HIGGINS, R.A.: Catalogue of the terracottas... op. cit. pág. 385-387, lám. 198, núm. 1452-1455, 1457.

(33) DELATTRE, Revd. P.: Une cachette de figurines de Deméter et de brüle parfums votifs à Carthage. "Comptes rendus de l'Académie des Inscriptions et Belles Lettres", 1923, pág. 359, núm. 1. ASTRUC, M.: Echanges entre Carthage et l'Espagne' d'après le témoignage de documents céramiques provenant d'anciennes fouilles. "Revue des 'Etudes Anciennes", LXIV, núm. 1-2. Bordeaux 1962, pág. 66. CINTAS, P. Ceramique punique. Inst. Hautes Etudes. Tunis III, Paris 1950, pág. 552. 76.

(34) NORDSTROM, S.: Los cartagineses en la costa alicantina. Alicante 1961, pág.

(35) ALMAGRO GORBEA, M.J.: Corpus de las terracotas de lbiza..., op. cit págs. 96-103, láms. XXXLX-XLV; págs. 230-234, láms CLX-CLXIV.

(36) Sobre la interpretación del depósito de Puig como una Favissa, vẻase M.P. SAN NICOLAS PEDRAZ: Testimonio del culto de las diosas Deméter-Perséphone en Ibiza. "Archivo Español de Arqueología" LIV, 1981, pág. 27-36.

(37) PICARD, G. CH.: op. cit. pág. 108-109. 
toda Grecia Megara, Egina, Locri, Perachora, Rebas, Siracusa, Corinto, Ialysos, Rodas, Camiros, Eleonte de Tracia.... así como en Sicilia Gela y Selinunte (38). El ejemplar más semejante al nuestro es el hallado en Locri, fechado a finales del siglo VI a, JC.

Esta figura representa claramente una sirena de aire, cuyo nombre deriva de la raíz $\sigma \epsilon \rho$, atar, aludiendo al papel que les atribuye la Mitología. La concepción antigua de estos seres fantásticos era la de una divinidad que personificaba las almas de los muertos y se las invocaban en el momento de la muerte, por lo que sus imágenes son frecuentes sobre los sepulcros como protectora del difunto (39).

Probablemente nuestra terracota fue importada directamente de Grecia o de las colonias: teniéndose en cuenta sus paralelos se podría fechar a finales del VI o principios de V a. JC.

6. Cabeza de una figura seguramente femenina (Lám. VII). Número de inventario de Museo 292. Altura conservada, $13^{\prime} 8 \mathrm{~cm}$. Barro de color grisáceo. Realizada con un solo molde, la parte posterior hueca. Completa. Se encuentra con grandes concreciones calcáreas en la superficie.

Se la puede apreciar las ondulaciones del cabello sobre la frente y en ambas sienes. Facciones borrosas ojos grandes y abultados. nariz larga y labios gruesos.

Fl arte es tosco y malo, debido al mal estado de la pieza es difícil situarla cronológicamente.

7. Brazo y mano de una figura (Lám. VIII). No consta número de inventario de Museo. Altura. 0’59 cm. Barro de color ocre claro. Corresponde a uno de los brazos de un busto a molde, que se añadía posteriormente, puesto que se ejecutaba aparte.

8. Brazo y mano de una figura similar a la anterior (Lám. IX). Número de inventario de Museo 928. Altura, 0'54 cm. Barro de color ocre claro. Reconstruido de dos fragmentos que unen perfectamente.

9. Brazo y mano de una figura (Lam. X). Número de inventario de Museo 25. Altura, $1^{\prime} 05 \mathrm{~cm}$. Barro de color ocre rojizo. Le falta casi todos los dedos excepto el pulgar. Corresponde a uno de los brazos de una figura de cuerpo entero.

(38) WINTER, F.: op. cit. lám. 226. BLINKENBERG, CHR.. op. cit. lám. 108, núm. 2313. BREITENSTEIN, N.: op. cit. lám. 18, núms. 165-166. HIGGINS, R.A.: Catalogue of the terracottas..., op. cit. págs. 52-55, lám. 16, núms. 75-78. MOLLARDBESQUES, S.: op. cit. pág. 23, lám XVII, B-136: pág. 50, lám. XXXIV, B-325.

(39) DANADONI, S. y MANSUELLI, G.A.: s.v. Sirene, en "Enciclopedia dell'Arte Antica". 


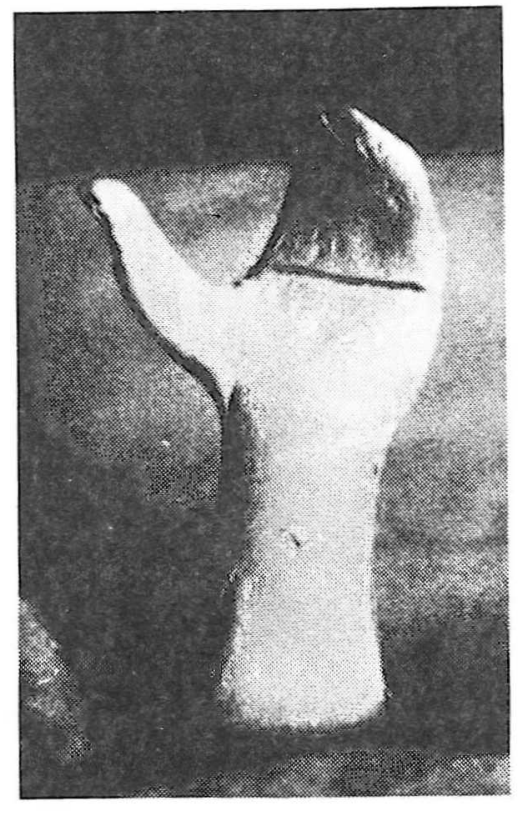

Lámina IX.

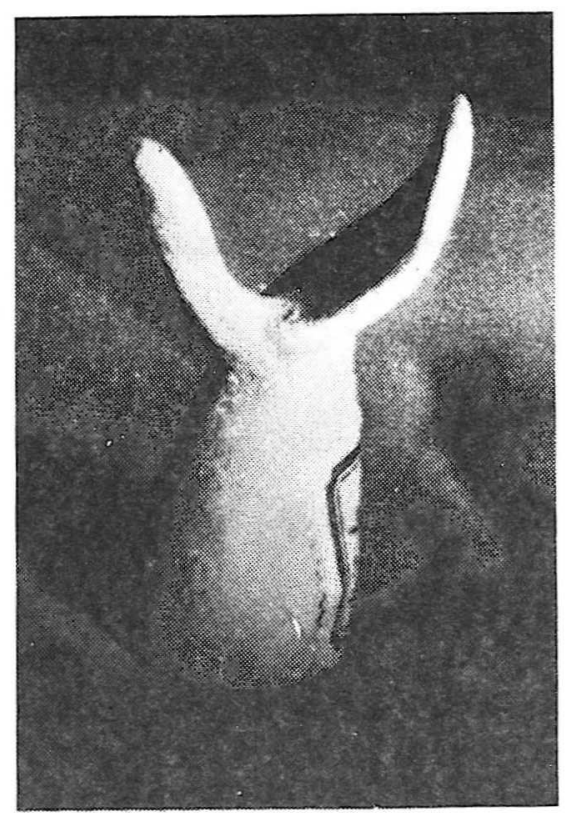

Lámina VIII.

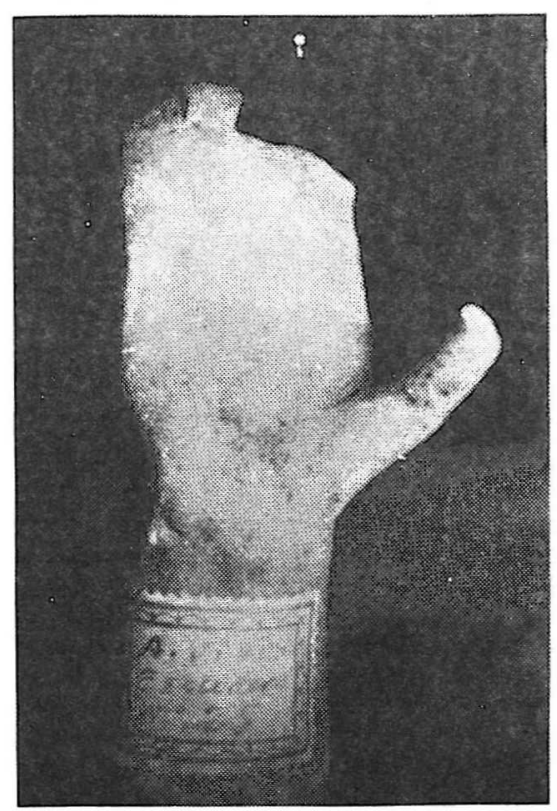

Lámina $X$. 